e ISSN-0976-7223 | Visit Us - www.researchjournal.co.in

DOI : 10.15740/HAS/IJAE/7.2/340-346

\title{
Standardization of the process of okara based (A by product of soymilk) dehydrated chunks
}

\section{SMITA KHODKE, SWAPNIL GHODEKAR AND PRAMODINI MORE}

Received : 04.03.2014; Revised : 03.08.2014; Accepted : 16.08.2014

See end of the Paper for authors' affiliation

Correspondence to :

\section{SMITA KHODKE}

Department of Agricultural Process Engineering, College of Agricultural Engineering and Technology, Marathwada Agricultural University, PARBHANI (M.S.) INDIA Email : sukhodke@rediffmail.com
- ABSTRACT : Chunks (Wadian), a traditional savoury food is usually legume-based and are more popular in northern India, while starch-based types are more popular in south India. Chunks are prepared from a thick, spiced batter, which is formed into balls of varying sizes (15-40g), and then dried. Traditionally, drying of these chunks is practiced under the sun. Hot air drying is an alternative method that decreases drying time and improves the quality of the dried product. Chunks were prepared using wet okara to partially replace black gram and green gram dhal to improve the nutritional quality. Okara and whole dhals were used in the formulations. The products were compared with control and market samples prepared with dhals only and then after sun-dried. The bulk density, optimum cooking time, water absorption capacity, hardness and sensory attributes revealed that the products with incorporation of 20 per cent okara and hot air drying at $60^{\circ} \mathrm{C}$ was found to be the most effective treatment to obtain better quality dehydrated chunks.

GEY WORDS : Okara, Traditional savoury food, Batter, Chunks, Drying

— HOW TO CITE THIS PAPER : Khodke, Smita, Ghodekar, Swapnil and More, Pramodini (2014). Standardization of the process of okara based (A by product of soymilk) dehydrated chunks. Internat. J. Agric. Engg., 7(2) : 340-346. 